\title{
Myeloid sarcomas: a histologic, immunohistochemical, and cytogenetic study
}

\author{
Borislav A Alexiev*1, Wenle Wang ${ }^{1}$, Yi Ning ${ }^{1}$, Saranya Chumsri², Ivana Gojo², \\ William H Rodgers ${ }^{1}$, Sanford A Stass ${ }^{1}$ and Xianfeng F Zhao ${ }^{1}$
}

\begin{abstract}
Address: ${ }^{1}$ Department of Pathology, University of Maryland Medical Center, 22 S Greene Street, Baltimore, MD, USA, 21201 and ${ }^{2}$ Department of Internal Medicine, Division Hematology Oncology, University of Maryland Medical Center, Marlene and Stewart Greenebaum Cancer Center, 22 S. Greene Street, Baltimore, MD, USA, 21201

Email: Borislav A Alexiev* - balexiev@umm.edu; Wenle Wang - wwang1234@gmail.com; Yi Ning - yning@som.umaryland.edu; Saranya Chumsri - schumsri@umm.edu; Ivana Gojo - Igojo@umm.edu; William H Rodgers - wrodgers@som.umaryland.edu; Sanford A Stass - SStass@som.umaryland.edu; Xianfeng F Zhao - fzhao@umm.edu

* Corresponding author
\end{abstract}

Published: 3I October 2007

Diagnostic Pathology 2007, 2:42 doi:10.1186/1746-1596-2-42
Received: 24 September 2007

Accepted: 31 October 2007

This article is available from: http://www.diagnosticpathology.org/content/2/I/42

(c) 2007 Alexiev et al; licensee BioMed Central Ltd.

This is an Open Access article distributed under the terms of the Creative Commons Attribution License (http://creativecommons.org/licenses/by/2.0), which permits unrestricted use, distribution, and reproduction in any medium, provided the original work is properly cited.

\begin{abstract}
Context. -: Myeloid sarcoma (MS) is a neoplasm of immature granulocytes, monocytes, or both involving any extramedullary site. The correct diagnosis of MS is important for adequate therapy, which is often delayed because of a high misdiagnosis rate.
\end{abstract}

Objective. -: To evaluate the lineage differentiation of neoplastic cells in MS by immunohistochemistry, and to correlate the results with clinicopathologic findings and cytogenetic studies.

Design. -: Histologic and immunohistochemical examinations were performed on formalin-fixed paraffin-embedded tissue samples from 13 cases of MS. They were classified according to the World Health Organization criteria. Chromosomal analysis data were available in II cases. Clinical, pathological, and cytogenetic findings were analyzed.

Results. -: The study included six male and seven female patients with an age range of 25 to 72 years (mean, 49.3 years) and a male to female ratio of I:I.2. MS de novo occurred in $4 / 13$ (3I\%) of cases examined. The most sensitive immunohistochemical markers were CD43 and lysozyme present in all cases with MS (13/I3, 100\%). All de novo MS showed a normal karyotype, monoblastic differentiation, and lack of CD34. The most common chromosomal abnormalities in MS associated with a hematopoietic disorder were trisomy 8 and inv(16) $(2 / 1 \mathrm{I}, 18 \%)$.

Conclusion. -: An immunohistochemical panel including CD43, lysozyme, myeloperoxidase (MPO), CD68 (or CDI63), CDII7, CD3 and CD20 can successfully identify the vast majority of MS variants in formalin-fixed paraffin-embedded tissue sections. The present report expands the spectrum of our knowledge showing that de novo MS has frequent monoblastic differentiation and frequently carries a normal karyotype. 


\section{Background}

Myeloid sarcoma (MS) is a tumor mass of myeloblasts or immature myeloid cells occurring in an extramedullary site or in the bone [1]. The tumor can involve any part of the body, but commonly involved sites include subperiosteal bone structures of the skull, paranasal sinuses, sternum, ribs, vertebrae, and pelvis; lymph nodes and skin are also common sites [1]. MS may occur de novo or concurrently with acute myeloid leukemia (AML) or a myeloproliferative disorder [1]. The rate of occurrence is approximately $1.4 \%$ to $9 \%$ of patients with AML $[2,3]$. MS is frequently mistaken for non-Hodgkin lymphoma (NHL), small round cell tumor (neuroblastoma, rhabdomyosarcoma, Ewing sarcoma/PNET, and medulloblastoma), and undifferentiated carcinoma. The diagnosis is missed in about $50 \%$ of cases when immunohistochemistry is not used [4]. The most common suggested diagnosis was that of a NHL [5].

The present study was designated to evaluate the lineage differentiation of neoplastic cells in MS by immunohistochemistry, and correlate the results with clinicopathologic findings and cytogenetic studies.

\section{Material}

Thirteen patients with a histologic diagnosis of myeloid sarcoma were included in the present study. The initial diagnosis was made on core biopsies ( 3 cases) and surgical specimens (10 cases). The specimens were fixed in $10 \%$ formaldehyde and embedded in paraffin. Fivemicron tissue sections were stained with hematoxylineosin. The use of paraffin blocks for this study meets Institutional Review Board and Health Insurance Portability and Accountability Act requirements, and has been approved by the Institutional Review Board at the University of Maryland.

\section{Immunohistochemistry}

Immunohistochemical staining was performed using an automated slide preparation system (Benchmark XT, Ventana, Tuscon, AZ), a Ventana Enhanced DAB Detection Kit (Ventana, Tucson, AZ), and commercially available prediluted monoclonal antibodies: CD163 (NeoMarkers), CD4 (Biocare Medical), myeloperoxidase, lysozyme, CD3, CD4, CD8, CD15, CD20, CD34, CD43, CD68, CD79a, CD117, Factor VIII (FVIII), and glycophorin A (all Ventana, Tucson, AZ).

\section{Chromosomal Study}

Chromosomal analysis was performed on tumor specimens from 11 patients at diagnosis. Cells were cultured in RPMI 1640 medium with 20\% fetal bovine serum for 24 and 48 hours, respectively. Metaphase cells were analyzed following standard G-banding method. Their karyotypes were interpreted according to the International System for Human Cytogenetic Nomenclature.

\section{Results}

\section{Demographic data}

The clinical findings are shown in Table 1. The study included six male and seven female patients with an age range of 25 to 72 years (mean, 49.3 years) and a male to female ratio of 1:1.2. MS de novo occurred in 4/13 (31\%) cases examined.

\section{Sites of involvement}

MS occurred in a variety of extramedullary sites (Table 1). Nine of thirteen cases with MS (69\%) had a synchronous involvement of the bone marrow by acute leukemia, myeloproliferative, or myelodysplastic disorder.

\section{Histology and immunohistochemistry}

The pathologic diagnoses are shown in Table 2.

Immature granulocytic sarcomas (IGS) were characterized by the presence of numerous (>90\%) blasts with high N/ $\mathrm{C}$ ratio, round or oval nucleus, dispersed chromatin and prominent nucleolus. The cytoplasm of the majority of neoplastic cells was agranular with a varying degree of basophilia. Eosinophilic granulation was notable in a minority of a cell population. The neoplastic cells in IGS showed reactivity with CD34, CD43, CD117, and lysozyme. MPO was present in a variable number of blasts, but always $<10 \%$. Focal weak reactivity of the neoplastic cells with antibodies to CD68 and/or CD163 was also noted. Differentiated granulocytic sarcomas (DGS) showed maturation to more mature neutrophils ( $>10 \%$ of neoplastic cells). The neoplastic cells in DGS showed strong reactivity with CD43, MPO, CD15, lysozyme, and

Table I: Clinical findings in patients with myeloid sarcoma

\begin{tabular}{rrll}
\hline Case & Age, year/sex & Site & Bone marrow \\
\hline 1 & $25 / M$ & Scrotum & Uninvolved \\
2 & $66 / M$ & Kidney & RAEB-2* \\
3 & $27 / M$ & Testis & AML, M2 \\
4 & $54 / F$ & Colon & AML, M2 \\
5 & $58 / M$ & Orbit & Uninvolved \\
6 & $72 / M$ & Skin & Uninvolved \\
7 & $46 / F$ & Lymph Node & Uninvolved \\
8 & $62 / F$ & Gingiva & Myelofibrosis \\
9 & $36 / F$ & Vagina & AML, MI \\
10 & $38 / M$ & T5, T7 & CML/BP** \\
11 & $51 / F$ & Gallbladder & AML, M5b \\
12 & $40 / F$ & Breast & AML, MI \\
13 & $38 / F$ & Breast & AML, M4 \\
& & &
\end{tabular}

*RAEB-2: Refractory anemia with excess blasts 2

**CML/BP: Chronic myelogeneous leukemia, blast phase 
Table 2: Pathologic diagnosis in patients with myeloid sarcomas

\begin{tabular}{ll}
\hline Case & Pathologic diagnosis \\
\hline 1 & Monoblastic sarcoma* \\
2 & Myelomonocytic sarcoma \\
3 & Granulocytic sarcoma, differentiated \\
4 & Granulocytic sarcoma, differentiated \\
5 & Monoblastic sarcoma* \\
6 & Monoblastic sarcoma* \\
7 & Monoblastic sarcoma* \\
8 & Myelomonocytic sarcoma \\
9 & Granulocytic sarcoma, immature \\
10 & Granulocytic sarcoma, differentiated \\
11 & Monocytic sarcoma \\
12 & Granulocytic sarcoma, immature \\
13 & Myelomonocytic sarcoma \\
\hline
\end{tabular}

\footnotetext{
* MS de novo.
}

variably expressed CD117. CD68 and CD163 were positive in $<20 \%$ of neoplastic cells.

Monoblastic sarcomas (MBLS) were composed of a large population $(>80 \%)$ of monoblasts. The neoplastic cells were large, with abundant eosinophilic cytoplasm, round or oval nuclei with dispersed chromatin and one or more prominent nucleoli. Promonocytes showed more irregular, delicately convoluted nuclear features. MBLS were strongly positive for CD43, lysozyme, CD68, CD163, weakly for CD4, and negative for CD34. Scattered MPO positive cells were also noted (Figs. 1, 2, 3, 4, 5, 6, 7).

In monocytic sarcoma (MCS), the majority of neoplastic cells showed marked nuclear lobulation and stained strongly with antibodies to CD43, lysozyme, CD68, CD163, and variably with MPO (Figs. 8, 9, 10, 11).

Myelomonocytic sarcomas (MMS) were characterized by proliferation of both neutrophilic and monocytic precursors with above described morphologic and immunohistochemical features each comprising $>20 \%$ of neoplastic cells. The cases were notable for increased numbers of eosinophils containing large eosinophilic granules in the cytoplasm.

The neoplastic cells in all MS examined did not react with antibodies to FVIII, and glycophorin A. T and B lymphocyte lineage-specific antigens such as CD3, CD20, and CD79a were typically absent.

All MS were morphologically and immunophenotypically analogous to their leukemic counterparts.

\section{Chromosomal study}

The cytogenetic findings are shown in Table 3. Chromosomal abnormalities were observed in 6/11 (55\%) cases examined. All patients with MS occurring de novo had a normal karyotype $(4 / 4,100 \%)$. The most common genetic abnormalities were the presence of an extra chromosome 8 and inv(16) (2/11, 18\%) (Fig. 12).

\section{Comments}

MS is a neoplasm of immature granulocytes, monocytes, or both involving any extramedullary site [6]. The neoplasm usually occurs in patients with acute myeloid leukemia, myelodysplastic or myeloproliferative disorder. It may rarely precede peripheral blood or bone marrow involvement, presenting a diagnostic challenge. In our study, all patients were adults with a slight female predominance. In agreement with previous reports, the neoplasms occurred in different locations including the orbit, gingiva, skin, breast, vertebral bodies, GI tract, and genitourinary system. [6-16].

With extensive morphological and immunohistochemical analyses, the MS were classified into five types: a) immature granulocytic sarcoma (IGS); b) differentiated granulocytic sarcoma (DGC); c) monoblastic sarcoma (MBLS); d) monocytic sarcoma (MS), and myelomonocytic sarcoma (MMS) (Table 2). These tumors were also morphologically and immunophenotypically analogous to their leukemic counterparts. In agreement with previous reports [5], CD43 and lysozyme were the most sensitive markers staining a large proportion of neoplastic cells in all tumors examined (13/13, 100\%). MPO and CD117 were the most sensitive of the markers for myeloid differentiation while monocytic precursors consistently strongly expressed CD68 and CD163. Differential diagnosis of MS includes several entities, the majority of which can be readily distinguished using a combination of morphologic and immunohistochemical evaluation. MS is frequently mistaken for malignant B-cell or T-cell lymphoma, especially when it presents without leukemic manifestation [3]. An incomplete workup may be misleading because NHL and MS share morphologic similarities and both express some leukocyte antigens, such as CD43 and CD45. In our study, B-cell and T-cell lymphomas were excluded by negative stains for CD20, CD79a and CD3, respectively. In addition, blastic NK cell lymphoma can mimic IGS, or MBLS. The neoplastic cells consistently express CD43, CD4, CD56, and, unlike MS, are negative for MPO, CD33, CD117, lysozyme, and CD68. Burkitt lymphoma could be excluded by negative immunoreactivity for B-cell-associated antigens, a relatively low proliferation rate, and lack of $\mathrm{t}(8 ; 14)$ or $\mathrm{t}(2 ; 8)$, and $\mathrm{t}(8 ; 22)$ translocations.

The findings are in agreement with previous observations and suggest that an immunohistochemical panel including CD43, MPO, CD117, CD68 (or CD163), CD3 and CD20 can successfully identify the majority of MS in formalin-fixed, paraffin-embedded tissue specimens [17-22]. 


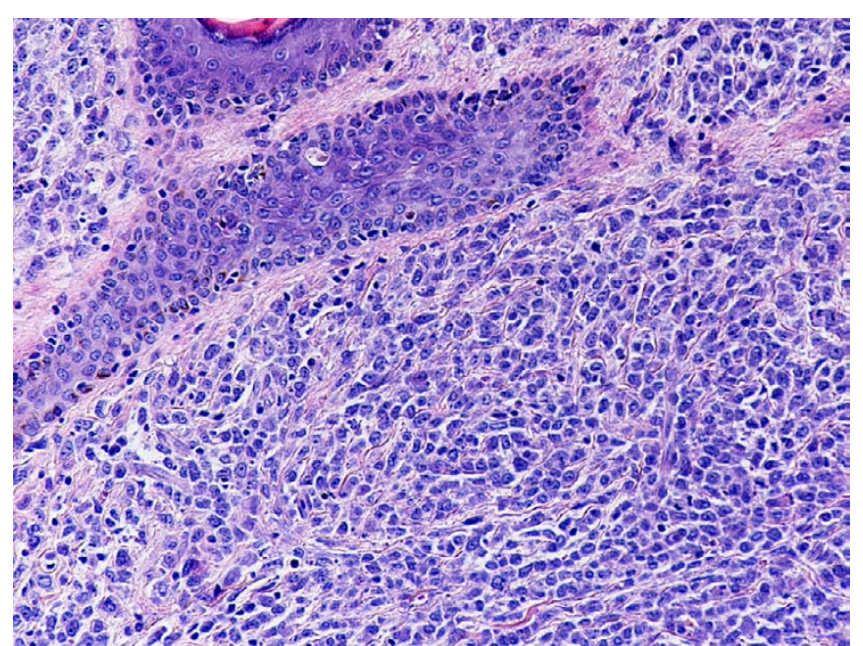

Figure I

Monoblastic sarcoma de novo, skin. (hematoxylin-eosin, $x$ 100).

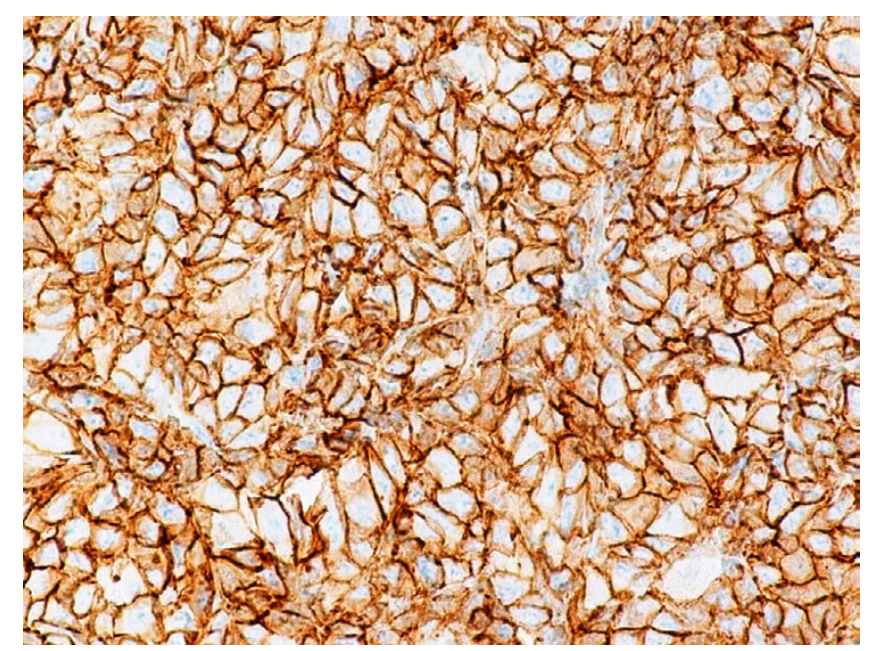

Figure 3

Monoblastic sarcoma de novo. Neoplastic cells are positive for CD43. (B-SA, anti-CD43, × 400).

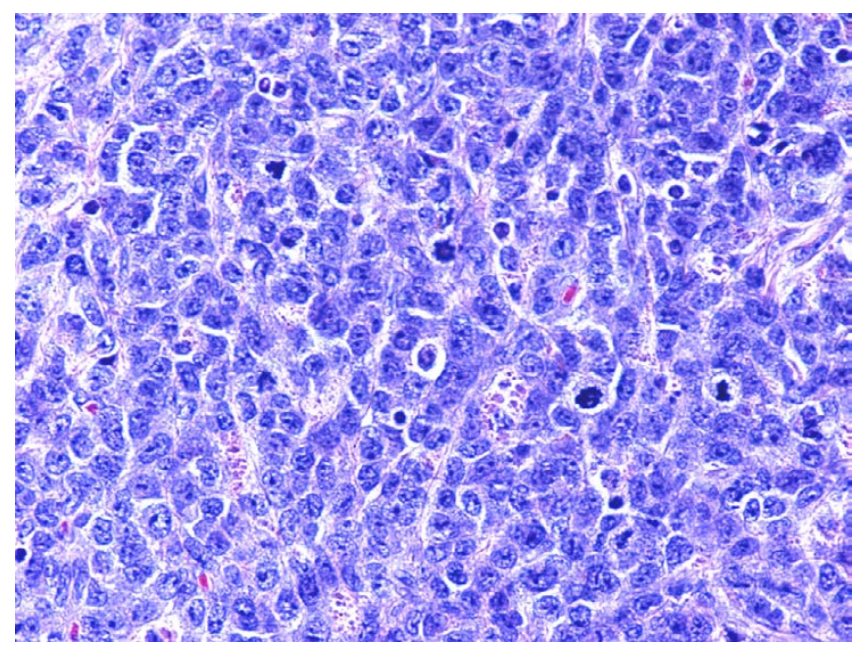

\section{Figure 2}

Monoblatic sarcoma de novo, skin. Multiple mitotic figures are seen. (hematoxylin-eosin, $\times 400$ ).

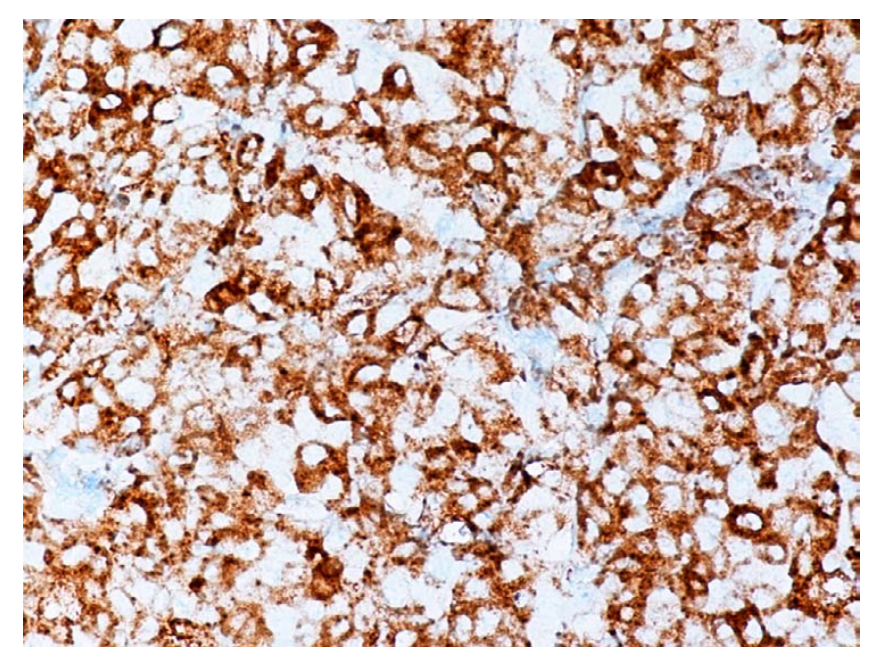

\section{Figure 4}

Monoblastic sarcoma de novo. Neoplastic cells are positive for CDI63. (B-SA, anti-CDI63, × 400). 


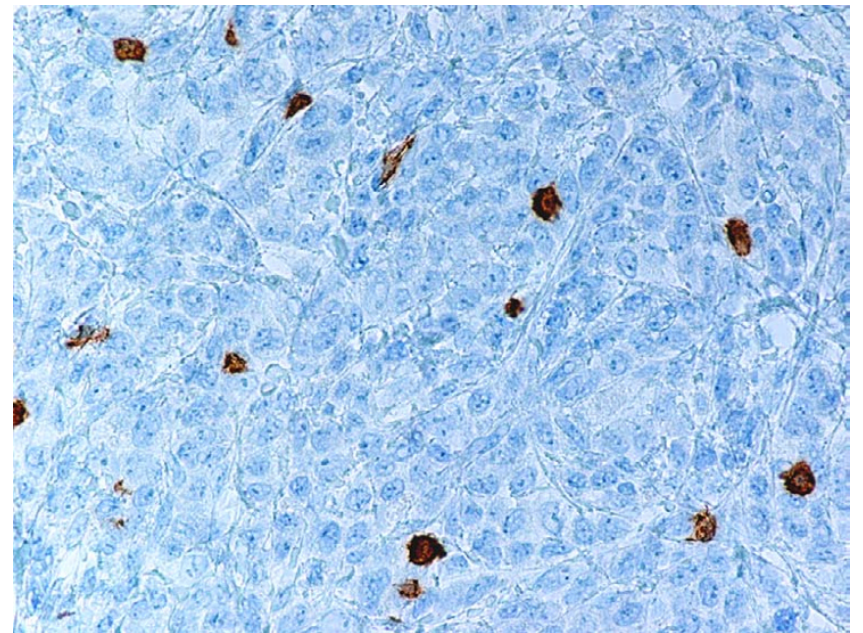

Figure 5

Monoblastic sarcoma de novo. Neoplastic cells are negative for CD3. Residual T-lymphocytes are positive with CD3 antibody. (B-SA, anti-CD3, x 400).

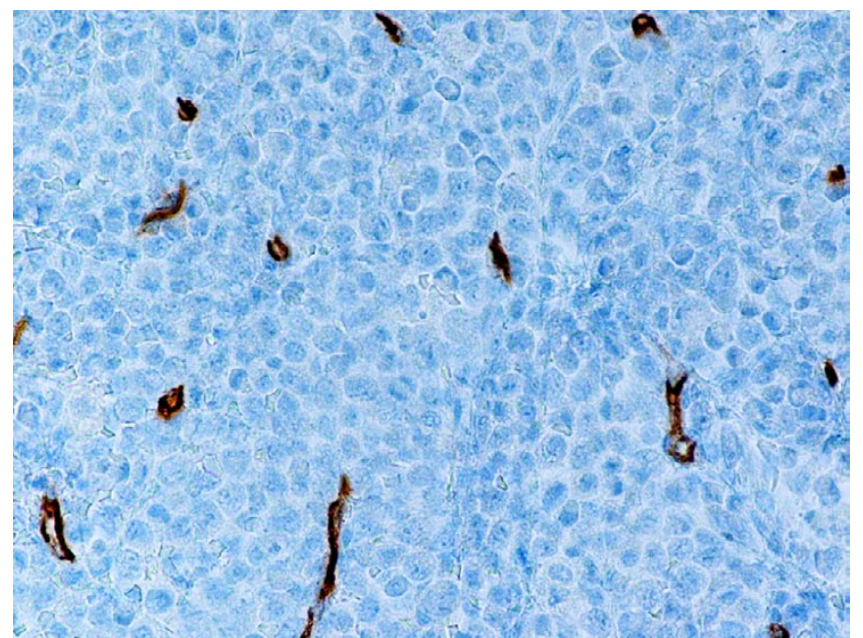

\section{Figure 6}

Monoblastic sarcoma de novo. One single neoplastic cell is positive for MPO. (B-SA, anti-MPO, × 400).

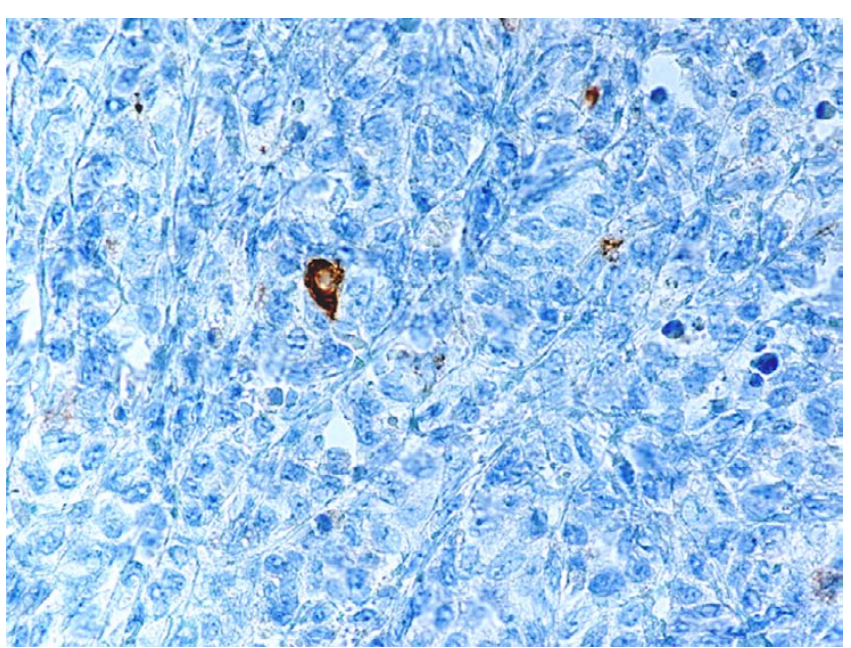

Figure 7

Monoblastic sarcoma de novo. Neoplastic cell are negative for CD34. Stain for CD34 reveals endothelial cells. (B-SA, anti-CD34, × 400).

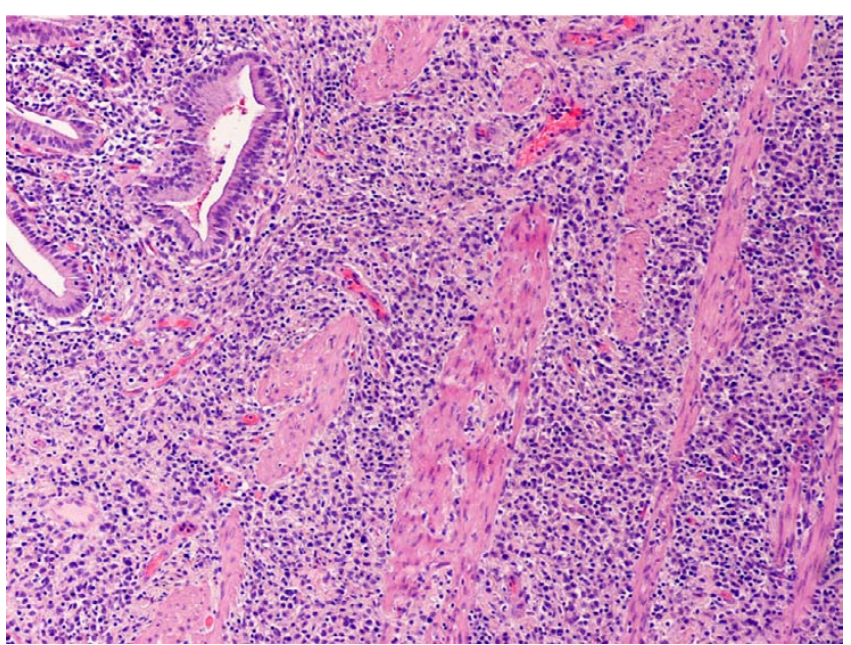

\section{Figure 8}

Monocytic sarcoma, gallbladder. (hematoxylin-eosin, $\times 100$ ). 


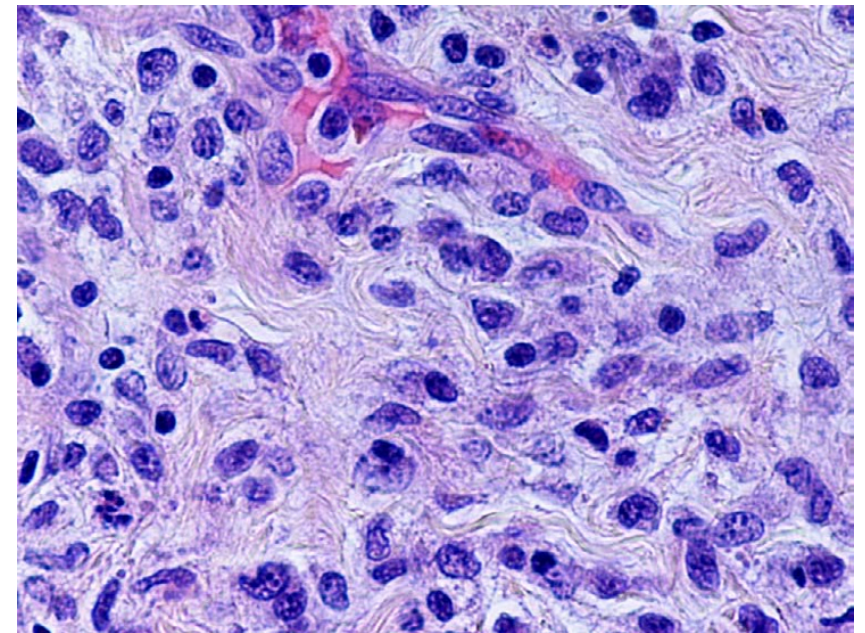

Figure 9

Monocytic sarcoma, gallbladder. Neoplastic cells have very dispersed chromatin and inconspicuous nucleoli. Note irregular and delicately convoluted nuclear configuration. (hematoxylin-eosin, $\times 400$ ).

Using the antibody panel mentioned above, we reached the correct diagnosis in all cases examined. In cases with megakaryoblastic and/or erythroblastic differentiation, diagnosis can be confirmed by inclusion of one or more lineage-specific markers, such as FVIII, CD41, CD61, glycophorin $\mathrm{A}$, and hemoglobin $\mathrm{A}$ in the diagnostic panel $[1,23]$.

MS has been described in association with a variety of chromosomal abnormalities [1,24]. In particular, $\mathrm{t}(8 ; 21)(\mathrm{q} 22 ; \mathrm{q} 22)$ and inv(16) are regarded as recurrent

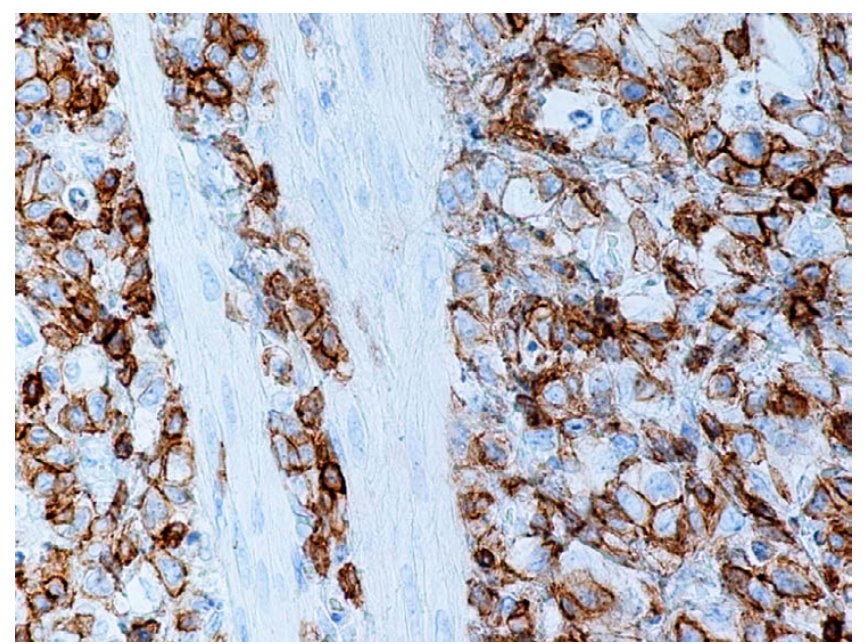

Figure 10

Monocytic sarcoma, gallbladder. Neoplastic cells are positive for CD43. (B-SA, anti-CD43, × 400).

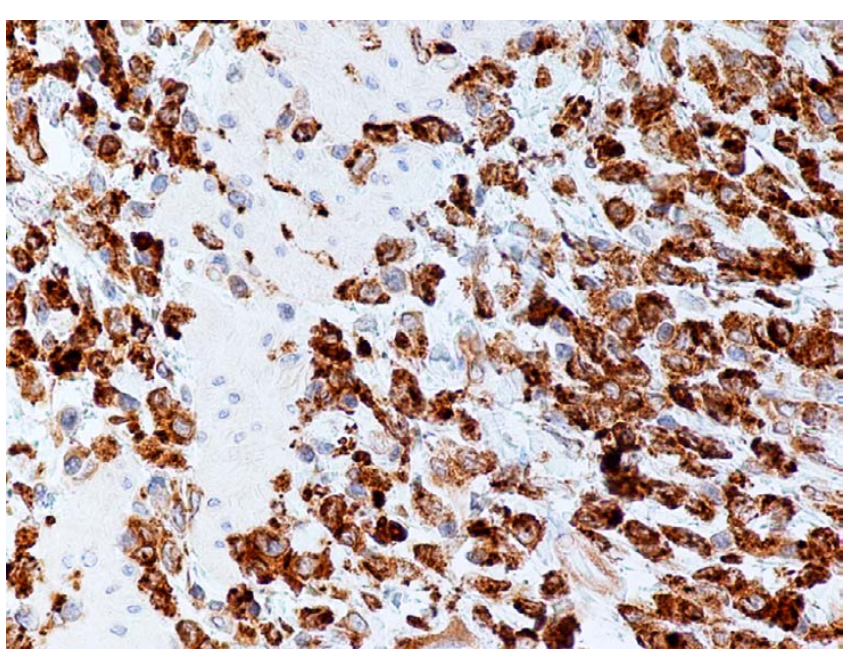

Figure II

Monocytic sarcoma, gallbladder. Neoplastic cells are positive for CD68. (B-SA, anti-CD68, × 400).

aberrations in GS $[1,3,9,15]$ while translocations involving 11q23 have been detected in MBLS [1]. In this study, chromosomal aberrations were detected in 55\% (6/11) of the cases. The commonest abnormalities were +8 , and $\operatorname{inv}(16)$ occurring in $18 \%(2 / 11)$ of MS. DGS $(n=1)$ and MCS $(\mathrm{n}=1)$ carried trisomy $8(\mathrm{n}=1)$ while $\operatorname{inv}(16)$ was observed in IGS $(\mathrm{n}=1)$ and MMS $(\mathrm{n}=1)$. The findings support the recent observation of Deeb et al. [24] who described chromosome 8 abnormalities as the most common genetic aberration in MS. In this study, all cases carrying chromosomal abnormalities $(6 / 6,100 \%)$ had simultaneous AML, myeloproliferative disorder or MDS.

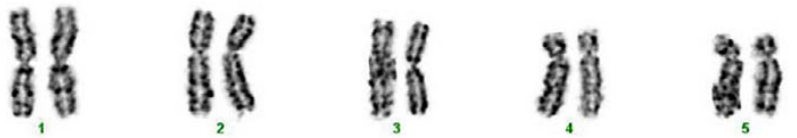

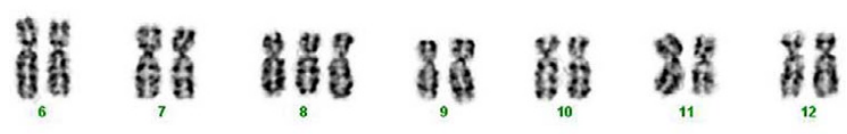

\begin{tabular}{|c|c|c|c|}
\hline 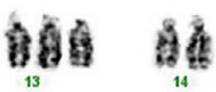 & $\underset{15}{3}$ & 88 & $\underset{17}{80}$ \\
\hline${ }_{20}^{818}$ & $\mathrm{~S}_{21}$ & $3_{22}^{2}$ & 80 \\
\hline
\end{tabular}

\section{Figure 12}

Monocytic sarcoma, gallbladder. Chromosomal analysis reveals trisomy 8 and trisomy 13. (standard G-banding) 
Table 3: Cytogenetic findings in patients with myeloid sarcoma

\begin{tabular}{|c|c|c|}
\hline Case & Cytogenetics & Pathologic diagnosis \\
\hline I & $46, X Y$ & Monoblastic sarcoma* \\
\hline 2 & $47, X Y,+21$ & Myelomonocytic sarcoma \\
\hline 3 & 46, XY, del(8)(q24.2) & DGS*** \\
\hline 4 & N/A & DGS**** \\
\hline 5 & $46, X X$ & Monoblastic sarcoma* \\
\hline 6 & $46, X Y$ & Monoblastic sarcoma* \\
\hline 7 & $46, X X$ & Monoblastic sarcoma* \\
\hline 8 & N/A & Myelomonocytic sarcoma \\
\hline 9 & $46, X X$ & IGS** \\
\hline 10 & $47, X Y,+8, t(9 ; 22)(q 34 ; q \mid I .2)$ & DGS*** \\
\hline 11 & $48, X X,+8,+13$ & Monocytic sarcoma \\
\hline 12 & $47, X X, t(4 ; 7)(p|2 ; p| \mid .2), \operatorname{lnv}(9)(p|2 q| 3), \operatorname{inv}(\mid 6)(p|3| q 22)$. & IGS** \\
\hline 13 & $46, X X$, inv $(16)(p \mid 3.1 q 22)$ & Myelomonocytic sarcoma \\
\hline
\end{tabular}

* MS de novo

** IGS: Immature granulocytic sarcoma

***DGS: Differentiated granulocytic sarcoma

Similar to what was reported by others [25], we found that inv(16) was associated with myelomonocytic differentiation in at least one case. $\operatorname{Inv}(16)$ was also identified in another case that was classified as IGS with multiple cytogenetic abnormalities. Furthermore, both cases involved the breast, in contrast to earlier reports of intestinal involvement by inv(16) positive MS with monocytic differentiation. All patients with de novo MS showed a normal karyotype $(4 / 4,100 \%)$, monoblastic differentiation, and lack of CD34. Previous studies revealed a correlation of monocytic differentiation, lack of CD34, and normal cytogenetics with nucleophosmin gene (NPM1) abnormalities [26]. In adults, NPM1 gene mutations have been identified in $50 \%$ to $60 \%$ of all AML cases with a normal karyotype [26]. Whether this newly identified molecular marker can aid in stratification of patients is under clinical investigation. In addition, a recent study showed a significant correlation between extramedullary involvement and coexpression of MCP-1/CCR2 by M4M5 blasts which might help to explain some aspects of the pattern of invasion in MS with monocytic differentiation [27].

The correct diagnosis of MS is important for adequate therapy, which is often delayed because of a high misdiagnosis rate [7]. Previous studies have indicated that the biologic behavior is dramatic irrespective of presentation, age, sex, phenotype and cytogenetics [25]. Conversely to that reported by Pileri et al. [25], other reports showed a shorter median survival of patients with chromosome 8 abnormalities [2] and better prognosis for patients with GS [9]. From our experience, the occurrence of GS in patients with hematological abnormalities has a negative impact on median survival and prognosis (unpublished observations).
The present report expands the spectrum of our knowledge showing that de novo MS has frequent monoblastic differentiation and frequently carries a normal karyotype. The most common genetic aberrations in MS associated with hematopoietic disorders were trisomy 8 and inv(16).

\section{Competing interests}

The author(s) declare that they have no competing interests.

\section{Authors' contributions}

BAA evaluated the H\&E and immunohistochemical stains, confirmed the diagnosis, designed the report and drafted the manuscript.

YN performed the cytogenetic studies.

SC and IG provided relevant clinical information.

WHR, SAS and XFZ provided consultation.

All authors read and approved the final manuscript.

\section{References}

I. Brunnung RD, Matutes E, Flandrin G, Vardiman J, Bennett J, Head D, Harris NL: Acute myeloid leukemias. In World Health Organization Classification of Tumors. Pathology and Genetics of Tumours of Haematopoietic and Lymphoid Tissue Edited by: Jaffe ES, Harris NL, Stein H, Vardiman JW. IARC Press; 2001:77-105.

2. Tsimberidou AM, Kantarjian HM, Estey E, Cortes JE, Verstovsek S, Faderl S, Thomas DA, Garcia-Manero G, Ferrajoli A, Manning JT, Keating MJ, Albitar M, O'Brien S, Giles Fj: Outcome in patients with nonleukemic granulocytic sarcoma treated with chemotherapy with or without radiotherapy. Leukemia 2003, 17:1 100-1103.

3. Zekry N, Klooster MJ, Raghavan R, Wang J: A 7-year-old child with a history of acute myeloid leukemia presenting with multiple gastrointestinal polyps. Arch Pathol Lab Med 2006, I 30:3-4.

4. Audouin J, Comperat E, Le Tourneau A, Camilleri-Broet S, Adida C, Molina T, Diebold J: Myeloid sarcoma: clinical and morpholog- 
ical criteria useful for diagnosis. Int I Surg Pathol 2003, I I:27I-282.

5. Menasce LP, Banerjee SS, Beckett E, Harris M: Extra-medullary myeloid tumour (granulocytic sarcoma) is often misdiagnosed: a study of 26 cases. Histopathol 1999, 34:391-398.

6. Valbuena JR, Admirand JH, Gualco G, Medeiros LJ: Myeloid sarcoma involving the breast. Arch Pathol Lab Med 2005, I 29:32-38.

7. Colella G, Tirelli A, Capone R, Rubini C, Guastafierro S: Myeloid sarcoma occuring in the maxillary gingiva: a case without leukemic manifestations. Int J Hematol 2005, 8 I: I 38-4I.

8. Antmen B, Haytac MC, Sasmaz I, Dogan MC, Ergin M, Tanyelli A: Granulocytic sarcoma of gingival: an unusual case with aleukemic presentation. J Periodontol 2003, 74:1514-1519.

9. Stein-Wexler R, Wootton-Gorges SL, West DC: Orbital granulocytic sarcoma: an unusual presentation of acute myelocytic leukemia. Pediatr Radiol 2003, 33:136-139.

10. Ojima H, Hasegawa T, Matsuno Y, Sakamoto M: Extramedullary myeloid tumour (EMMT) of the gallbladder. J Clin Pathol 2005, 58:2II-2I3.

II. Yavuz S, Paydas S, Disel U, Erdogan S: Ovarian granulocytic sarcoma. Leuk Lymphoma 2004, 45: I83-185.

12. Oliva E, Ferry JA, Young RH, Prat J, Srigley JR, Scully RE: Granulocytic sarcoma of the female genital tract: a clinicopathologic study of I I cases. Am J Surg Pathol 1997, 21: I I56-I I65.

13. Valbuena JR, Admirand JH, Lin P, Medeiros LJ: Myeloid sarcoma involving the testis. Am J Clin Pathol 2005, I 24:445-452.

14. Garcia MG, Deavers MT, Knoblock RJ, Chen W, Tsimberidou AM, Manning JT Jr, Medeiros LJ: Myeloid sarcoma involving the gynecologic tract: a report of II cases and review of the literature. Am J Clin Pathol 2006, I 25:783-790.

15. Al-Quran SZ, Olivares A, Lin P, Stephens TW, Medeiros LJ, Abruzzo LV: Myeloid sarcoma of the urinary bladder and epididymis as a primary manifestation of acute myeloid leukemia with inv(16). Arch Pathol Lab Med 2006, 130:862-866.

16. Gopal S, Marcussen S, Dobin SM, Koss W, Donner LR: Primary myeloid sarcoma of the testicle with $t(15 ; 17)$. Cancer Gen Cytogen 2005, I57:148-150.

17. Li JM, Liu WP, Zhang MH, Wei X, Gu JM, Han AJ, Wu WQ, Chen XY: Clinicopathologic and immunophenotypic analysis of myeloid sarcoma. Zhonghua Bing Li Xue Za Zhi 2006, 35:606-6II.

18. Liu YH, Zhuang HG, Liao XB, Luo XL, Cai XL, Luo DL: Diagnosis and differential diagnosis of granulocytic sarcomas. Zhonghua Xue Ye Xue Za Zhi 2003, 24:568-57I.

19. Ritter JH, Goldstein NS, Argenyi Z, Wick MR: Granulocytic sarcoma: an immunohistologic comparison with peripheral Tcell lymphoma in paraffin sections. J Cutan Pathol 1994, 21:207-216.

20. Chang CC, Eshoa C, Kampalath B, Shidham VB, Perkins S: Immunophenotypic profile of myeloid cells in granulocytic sarcoma by immunohistochemistry. Correlation with blast differentiation in bone marrow. Am \& Clin Pathol 2000, I | 4:807-8II.

21. Hudock J, Chatten J, Miettinen M: Immunohistochemical evaluation of myeloid leukemia infiltrates (granulocytic sarcomas) in formaldehyde-fixed, paraffin-embedded tissue. Am J Clin Pathol 1994, 102:55-60.

22. Traweek ST, Arber DA, Rappaport H, Brynes RK: Extramedullary myeloid cell tumors. An immunohistochemical and morphological study of 28 cases. Am J Surg Pathol 1993, 17:101 I-1019.

23. Hirose Y, Masaki Y, Shimoyama K, Sugai S, Nojima T: Granulocytic sarcoma of megakaryoblastic differentiation in the lymph nodes terminating as acute megakaryoblastic leukemia in a case of chronic idiopathic myelofibrosis persisting for 16 years. Eur J Hematol 200I, 67: 194-198.

24. Deeb G, Baer MR, Gaile DP, Sait SN, Barcos M, Wetzler M, Conroy JM, Nowak NJ, Cowell JK, Cheney RT: Genomic profiling of myeloid sarcoma by array comparative genomic hybridization. Genes Chromosomes Cancer 2005, 44:373-383.

25. Pileri SA, Ascani S, Cox MC, Campidelli C, Bacci F, Piccioli M, Piccaluga PP, Agostinelli C, Asioli S, Novero D, Bisceglia M, Ponzoni M, Gentile A, Rinaldi P, Franco V, Vincelli D, Pileri A Jr, Gasbarra R, Falini $B$, Zinzani PL, Baccarani M: Myeloid sarcoma: clinico-pathologic, phenotypic and cytogenetic analysis of 92 adult patients. Leukemia 2007, 21:340-350.
26. Chen W, Rassidakis GZ, Medeiros LJ: Nucleophosmin gene mutations in acute myeloid leukemia. Arch Pathol Lab Med 2006, 130:1687-1692.

27. Cignetti A, Vallario A, Roato I, Circosta P, Strola G, Scielzo C, Allione B, Garetto L, Caligaris-Cappio F, Ghia P: The characterization of chemokine production and chemokine receptor expression reveals possible functional cross-talks in AML blasts with monocytic differentiation. Exp Hematol 2003, 31:495-503.
Publish with Bio Med Central and every scientist can read your work free of charge

"BioMed Central will be the most significant development for disseminating the results of biomedical research in our lifetime. "

Sir Paul Nurse, Cancer Research UK

Your research papers will be:

- available free of charge to the entire biomedical community

- peer reviewed and published immediately upon acceptance

- cited in PubMed and archived on PubMed Central

- yours - you keep the copyright

Submit your manuscript here:

http://www.biomedcentral.com/info/publishing_adv.asp
BiolMedcentral 